\title{
Acaricidal activity of extracts from Ligularia virgaurea against the Sarcoptes scabiei mite in vitro
}

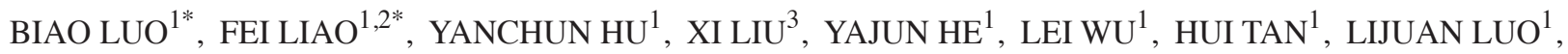 \\ YANCHENG ZHOU $^{1}$, QUAN MO ${ }^{1}$, JUNLIANG DENG ${ }^{1}$ and YAHUI WEI ${ }^{4}$
}

\author{
${ }^{1}$ Key Laboratory of Animal Disease and Human Health of Sichuan Province, College of Veterinary Medicine, \\ Sichuan Agricultural University, Wenjiang, Sichuan 611130; ${ }^{2}$ Qiandongnan Prefectural Center for Animal Disease Control and \\ Prevention, Kaili, Guizhou 556000; ${ }^{3}$ Ganzi Institute of Animal Husbandary, Kangding, Sichuan 626000; \\ ${ }^{4}$ Key Laboratory of Resource Biology and Biotechnology in Western China, School of Life Science, \\ Northwest University, Xi'an, Shaanxi 710069, P.R. China
}

Received August 21, 2014; Accepted April 8, 2015

DOI: 10.3892/etm.2015.2503

\begin{abstract}
The aim of the present study was to investigate the acaricidal activity of Ligularia virgaurea. An extract was prepared by refluxing with ethanol and steam distillation, and its toxic effect was tested in vitro against Sarcoptes scabiei. The data from the toxicity tests were analyzed using a complementary log-log (CLL) model. The ethanol extract exhibited strong acaricidal activity against these mites; at a concentration of $2 \mathrm{~g} / \mathrm{ml}$ it killed all $S$. scabiei within $2 \mathrm{~h}$ and at $1 \mathrm{~g} / \mathrm{ml}$ it killed all S. scabiei within $6 \mathrm{~h}$. Similarly, 2, 1, 0.5 and $0.25 \mathrm{~g} / \mathrm{ml}$ concentrations of the extract had strong toxicity against $S$. scabiei, with median lethal time $\left(\mathrm{LT}_{50}\right)$ values of $0.716,1.741,2.968$ and $4.838 \mathrm{~h}$, respectively. The median lethal concentration $\left(\mathrm{LC}_{50}\right)$ values were $1.388,0.624,0.310$ and $0.213 \mathrm{~g} / \mathrm{ml}$ for Scabies mite in 1, 2, 4 and $6 \mathrm{~h}$, respectively. The results indicate that the $L$. virgaurea extract has strong acaricidal activity and may be exploited as a novel treatment for the effective control of acariasis in animals.
\end{abstract}

\section{Introduction}

Acariasis in animals, a common veterinary skin disease, may reduce the productivity and the quality of products obtained from animals, and can even lead to death (1). At present, various chemical agents are widely used to treat and control psoroptic and sarcoptic mange in veterinary clinics, and

Correspondence to: Professor Yanchun Hu, Key Laboratory of Animal Disease and Human Health of Sichuan Province, College of Veterinary Medicine, Sichuan Agricultural University, 211 Huimin Road, Wenjiang, Sichuan 611130, P.R. China

E-mail: yanchunhu@126.com

\section{${ }^{*}$ Contributed equally}

Key words: acaricidal activity, Ligularia virgaurea, Sarcoptes scabiei, toxic effect relatively good treatment effectiveness has been obtained with certain drugs, including ivermectin and abamectin. However, the use of chemicals could result in resistance in target species, toxicity and environmental hazards (2).

Ligularia Cass. of the family Compositae or Asteraceae is a genus highly diversified in the eastern Qinghai-Tibet Plateau region and adjacent areas, where $>100$ species exist $(3,4)$. The Ligularia Cass. genus is one of the large genera in the Compositae-Senecioneae-Tussilagininae classification (5). Ligularia virgaurea is one of the main species of Ligularia Cass., and is a noxious weed widely distributed in the alpine grassland of the eastern Qinghai-Tibet Plateau (6). Ligularia Cass. has been used for medicinal purposes, particularly for the treatment of jaundice, scarlet fever, rheumatoid arthritis and hepatic function failure (7). Extracts of this genus of plants have been reported to have antioxidant (8), analgesic, anti-inflammatory (9) and antitumor activity (10); anti-ulcerogenic (11), anti-obesity (12) and antihepatotoxic effects (13) and anticomplement activity (14). However, to the best of our knowledge, the acaricidal activity of $L$. virgaurea has not been investigated. The aim of the present study was to evaluate the possible acaricidal activity of an ethanol extract of L. virgaurea against Sarcoptes scabiei.

\section{Materials and methods}

Plant material and extraction. L. virgaurea was collected from Ganzi in Sichuan Province, southwest China in July 2013. A thermal refluxing method was used to extract the biological components into ethanol, as previously described (15). Following the concentration of the extract by the evaporation of ethanol, the extract was diluted with distilled water containing glycerin (10\%) to varying concentrations.

Mites. The S. scabiei mites were isolated from the scabs and ear cerumen of the infested legs and ears of naturally infected rabbits. The scabs and ear cerumen were placed in Petri dishes and incubated at $35^{\circ} \mathrm{C}$ for $30 \mathrm{~min}$ in an incubator. The adult mites were then collected for testing. Following the collec- 
tion of the samples, the rabbits were treated immediately. Institutional ethical and animal care guidelines of South China Agricultural University Experimental Animal Ethics Committee were adhered to during the sampling exercise, and all procedures were conducted in accordance with the Guide for the Care and Use of Laboratory Animals of the National Institutes of Health (8th ed, 2012).

In vitro assay of acaricidal activity. The ethanol extract was diluted to concentrations of 2, $1,0.5$ and $0.25 \mathrm{~g} / \mathrm{ml}$ with $10 \%$ glycerin, and $0.5-\mathrm{ml}$ samples of the extract were added to Petri dishes (diameter, $10 \mathrm{~cm}$; height, $2 \mathrm{~cm}$ ) with filter paper chips to absorb the liquid.

To test the activity against $S$. scabiei, 10 specimens were placed on the filter paper in the Petri dishes and incubated at $25^{\circ} \mathrm{C}$ under $75 \%$ relative humidity for $0.5,1,2,4$ or $6 \mathrm{~h}(16,17)$. Three replicates were performed for each concentration of the extract. Three Petri dishes containing $0.5 \mathrm{ml}$ distilled water and glycerin $(16,18)$ acted as an untreated (negative) control, and $2 \%$ ivermectin was used as the positive control. The mites were regularly stimulated with a needle to determine their viability, and mites were recorded as dead if no reaction was shown (19).

Statistical analysis. All computations were conducted using SPSS statistical software (version 20.0; SPSS, Inc., Chicago, IL, USA) (20). The significance of differences in the mean mite mortality between different concentrations was calculated using a probability method. The median lethal time value $\left(\mathrm{LT}_{50}\right)$ and the median lethal concentration value $\left(\mathrm{LC}_{50}\right)$ were calculated by the complementary log-log (CLL) model (21).

\section{Results}

Considerable differences in acaricidal activity were observed among the different concentrations of the ethanol extract. The highest concentration of the extract $(2 \mathrm{~g} / \mathrm{ml})$ caused $100 \%$ mortality in the test mites. In the negative control group, treated with $10 \%$ glycerin, the mites remained alive after the 6-h treatment period (Fig. 1). In addition, in the ivermectin-treated positive control group, a number of the mites remained alive in the sample following the 6-h treatment period. This may be because the $S$. scabiei test mites had developed resistance to ivermectin. Mortality rates for the mites treated with the four concentrations of the extract are shown in Table I. The toxicity of the ethanol extract was evaluated using a CLL model. Pearson's Chi-square test and the Hosmer-Lemeshow goodness-of-fit statistic indicated that the data fitted the CLL model. The $\mathrm{LT}_{50}$ and $\mathrm{LC}_{50}$ values of the ethanol extract against $S$. scabiei are shown in Tables II and III, respectively. The ethanol extract demonstrated strong toxicity to mites, and its activity was concentration- and time-dependent. The results indicate that an ethanol extract of $L$. virgaurea at concentrations of 2,1 and $0.5 \mathrm{~g} / \mathrm{ml}$ was highly toxic to $S$. scabiei. The $\mathrm{LT}_{50}$ values for solutions of the extract at concentrations of 2,1, 0.5 and $0.25 \mathrm{~g} / \mathrm{ml}$ were $0.716,1.741,2.968$ and $4.838 \mathrm{~h}$, respectively, and the $\mathrm{LC}_{50}$ values for $1,2,4$ and $6 \mathrm{~h}$ treatment times were $1.388,0.624$, 0.310 and $0.213 \mathrm{~g} / \mathrm{ml}$, respectively.

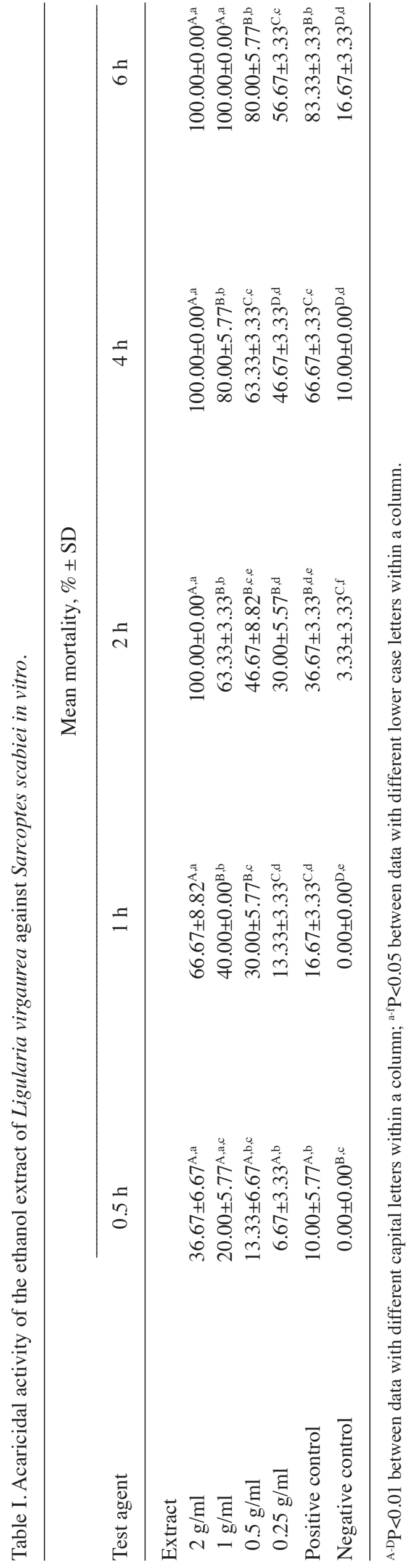


Table II. Probit regression analysis of the toxicity $\left(\mathrm{LT}_{50}\right)$ of the ethanol extract of Ligularia virgaurea against Sarcoptes scabiei in vitro.

\begin{tabular}{lccc}
\hline Concentration & Regression equation & LT $_{50}(95 \% \mathrm{FL}), \mathrm{h}$ & Pearson Chi-square \\
\hline $2 \mathrm{~g} / \mathrm{ml}$ & $\mathrm{y}=1.894 \mathrm{x}-1.357$ & $0.716(0.490-0.892)$ & 0.521 \\
$1 \mathrm{~g} / \mathrm{ml}$ & $\mathrm{y}=0.500 \mathrm{x}-0.871$ & $1.741(1.219-2.224)$ & 3.606 \\
$0.5 \mathrm{~g} / \mathrm{ml}$ & $\mathrm{y}=0.312 \mathrm{x}-0.926$ & $2.968(2.263-3.765)$ & 2.567 \\
$0.25 \mathrm{~g} / \mathrm{ml}$ & $\mathrm{y}=0.270 \mathrm{x}-1.306$ & $4.838(3.940-6.427)$ & 2.753 \\
\hline
\end{tabular}

$\mathrm{LT}_{50}$, median lethal time; FL, fiducial limits.

Table III. Probit regression analysis of the toxicity $\left(\mathrm{LC}_{50}\right)$ of the ethanol extract of Ligularia virgaurea against Sarcoptes scabiei in vitro.

\begin{tabular}{lccc}
\hline Time $(\mathrm{h})$ & Regression equation & $\mathrm{LC}_{50}(95 \% \mathrm{FL}), \mathrm{g} / \mathrm{ml}$ & Pearson Chi-square \\
\hline 1 & $\mathrm{y}=0.777 \mathrm{x}-1.078$ & $1.388(1.076-1.922)$ & 1.161 \\
2 & $\mathrm{y}=1.501 \mathrm{x}-0.936$ & $0.624(0.427-0.807)$ & 1.770 \\
4 & $\mathrm{y}=1.423 \mathrm{x}-0.441$ & $0.310(0.058-0.504)$ & 0.634 \\
6 & $\mathrm{y}=3.259 \mathrm{x}-0.694$ & $0.213(-0.092-0.322)$ & 0.330 \\
\hline
\end{tabular}

$\mathrm{LC}_{50}$, median lethal concentration; FL, fiducial limits.

A

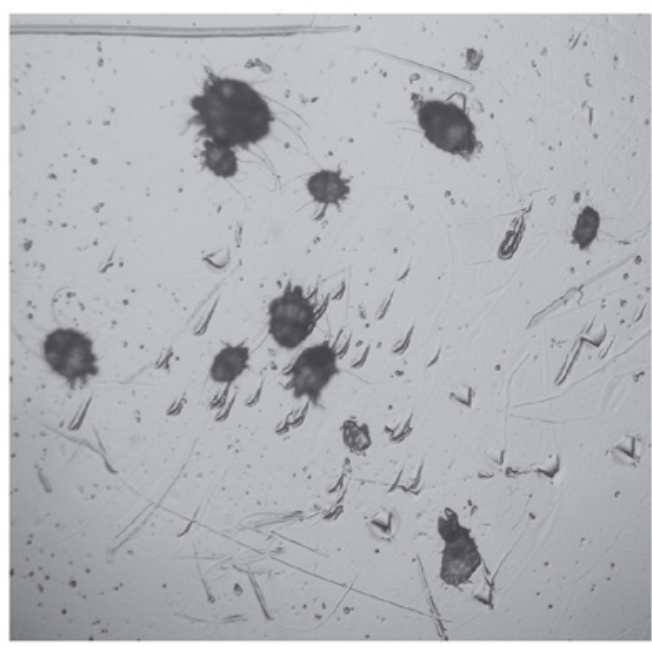

B

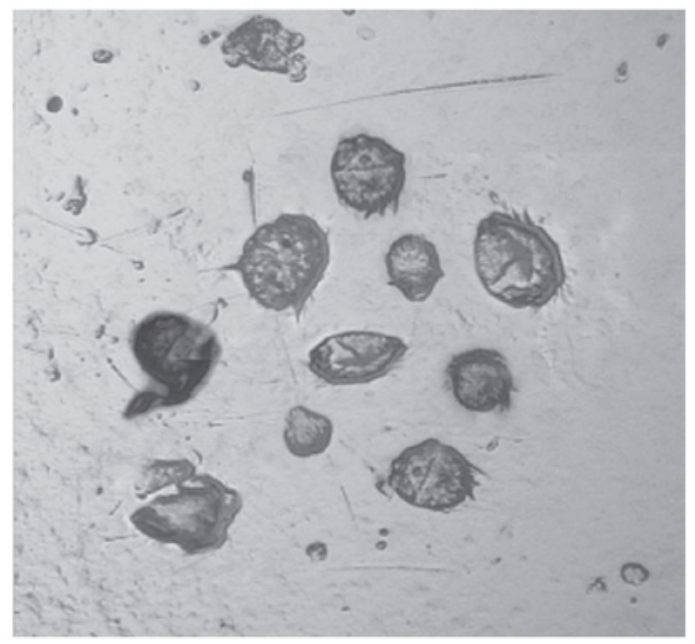

Figure 1. Samples of the mites after $6 \mathrm{~h}$ of treatment. (A) Negative control group (10\% glycerin), two mites had died; (B) experimental control group (ethanol extract with $2 \mathrm{~g} / \mathrm{ml}$ ).

\section{Discussion}

The results of this study demonstrate for the first time, to the best of our knowledge, that an ethanol extract of L. virgaurea has strong acaricidal activity. The extract, obtained from L. virgaurea by refluxing in ethanol, exhibited a strong toxic effect against S.scabiei. The toxicity of the extract was shown to be time-and concentration-dependent. Similareffects have been observed for an ethanol extract of Eupatorium adenophorum against $S$. scabiei (17,22), 9-oxo-10,11-dehydroageraphorone extracted from E. adenophorum against $S$. scabiei and Psoroptes cuniculi in vitro $(16,23)$, and for neem oil against
Amblyomma variegatum (24). The results of the present study suggest that the ethanol extract from $L$. virgaurea contains acaricidal component(s). It is likely that the acaricidal component(s) are soluble in organic solvents, such as alcohol, methanol and acetone, and is consistent with previous observation that the acaricidal components obtained from natural plants are volatile compounds $(25,26)$. Although $L$. virgaurea is regarded as a weed, this study provides a basis for its utilization in the development of plant-derived acaricidal drugs. These preliminary results indicate that $L$. virgaurea may be a source of novel acaricidal compounds that are able to effectively control mites in livestock. Further systematic studies are 
warranted to identify the active compounds in $L$. virgaurea and to evaluate them in clinical trials, animal acute toxicity tests and safety tests. Previous studies have shown that some of the effective components from $L$. virgaurea are not toxic to humans or animals (27). Following further in-depth evaluation, L. virgaurea, as a potent herbal drug, may have the potential to be more widely applied in treatments for humans and animals.

\section{Acknowledgements}

This study was supported by the Special Fund for Agroscientific Research in the Public Interest (grant. no. 201203062) and the Science and Technology Support Program of Sichuan Province (grant. no. 2015SZ0201).

\section{References}

1. Shang XF, Miao XL, Wang DS, et al: Acaricidal activity of extracts from Adonis coerulea Maxim. against Psoroptes cuniculi in vitro and in vivo. Vet Parasitol 195: 136-141, 2013.

2. Borges FA, Almeida GD, Heckler RP, Lemes RT, Onizuka MK and Borges DG: Anthelmintic resistance impact on tropical beef cattle productivity: effect on weight gain of weaned calves. Trop Anim Health Pro 45: 723-727, 2013.

3. Liu JQ, Wang YJ, Wang AL, Hideaki $O$ and Abbott RJ: Radiation and diversification within the Ligularia-Cremanthodium-Parasenecio complex (Asteraceae) triggered by uplift of the Qinghai-Tibetan Plateau. Mol Phylogenet Evol 38: 31-49, 2006.

4. Tori M, Honda K, Nakamizo H, et al: Chemical constituents of Ligularia virgaurea and its diversity in southwestern Sichuan of China. Tetrahedron 62: 4988-4995, 2006.

5. Liu SW, Deng DS and Liu JQ: The origin, evolution and distribution of Ligularia Cass. (Compositae). Zhi Wu Fen Lei Xue Bao 32: 514-525, 1994 (In Chinese).

6. Ma R, Wang M, Zhao K, Guo S, Zhao Q and Sun K: Allelopathy of aqueous extract from Ligularia virgaurea, a dominant weed in psychro-grassland, on pasture plants. Ying Yong Sheng Tai Xue Bao 17: 845-850, 2006 (In Chinese).

7. Bae JH, Yu SO, Kim YM, et al: Physiological activity of methanol extracts from Ligularia fischeri and their hyperplasia inhibition activity of cancer cell. J Bio-Environ Control 18: 67-73, 2009 (In Korean).

8. Shang YF, Kim SM, Song DG, Pan CH, Lee WJ and Um BH: Isolation and identification of antioxidant compounds from Ligularia fischeri. J Food Sci 75: C530-C535, 2010.

9. Lee KH and Choi EM: Analgesic and anti-inflammatory effects of Ligularia fischeri leaves in experimental animals. J Ethnopharmacol 120: 103-107, 2008.

10. Lee DK, Kim JK, Kim JS et al: Inhibitory effect of Ligularia Stenocephala on the cancer metastasis. Nat Prod Sci 18: 89-96, 2012.
11. Lee BI, Nugroho A, Bachri MS, et al: Anti-ulcerogenic effect and HPLC analysis of the caffeoylquinic acid-rich extract from Ligularia stenocephala. Biol Pharm Bull 33: 493-497, 2010.

12. Nugroho A, Bachri MS, Choi JW, et al: The inhibitory effect of the caffeoylquinic acid-rich extract of Ligularia stenocephala leaves on obesity in the high fat diet-induced rat. Nat Prod Sci 16: 80-87, 2010.

13. Choi J, Park JK, Lee KT, et al: In vivo antihepatotoxic effects of Ligularia fischeri var. spiciformis and the identification of the active component, 3,4-dicaffeoylquinic acid. J Med Food 8: 348-352, 2005.

14. Moon HI, Lee JH and Lee YC: Inhibitory effects of organic solvent extracts from Korean local plants on the complement classical pathway. Immunopharm Immunot 34: 12-14, 2012.

15. Cetin H, Cilek J, Oz E, Aydin L, Deveci O and Yanikoglu A: Acaricidal activity of Satureja thymbra L. essential oil and its major components, carvacrol and $\gamma$-terpinene against adult Hyalomma marginatum (Acari: Ixodidae). Vet Parasitol 170: 287-290, 2010.

16. Liao F, Hu Y, Tan H, et al: Acaricidal activity of 9-oxo-10, 11-dehydroageraphorone extracted from Eupatorium adenophorum in vitro. Exp Parasitol 140: 8-11, 2014.

17. Nong X, Ren YJ, Wang JH, Xie Y, Fang CL, Yang DY, et al: Clinical efficacy of botanical extracts from Eupatorium adenophorum against the Sarcoptes scabiei (Sarcoptidae: Sarcoptes) in rabbits. Vet Parasitol 195: 157-164, 2013.

18. Fichi G, Flamini G, Giovanelli F, Otranto D and Perrucci S: Efficacy of an essential oil of Eugenia caryophyllata against Psoroptes cuniculi. Exp Parasitol 115: 168-172, 2007.

19. Pasay C, Mounsey K, Stevenson G, et al: Acaricidal activity of eugenol based compounds against scabies mites. PLoS One 5: e12079, 2010

20. Zhang L, Koyyalamudi SR, Jeong SC, et al: Antioxidant and immunomodulatory activities of polysaccharides from the roots of Sanguisorba officinalis. Int J Biol Macromol 51: 1057-1062, 2012.

21. Qiu J, Song F, Mao L, Tu J and Guan X: Time-dose-mortality data and modeling for the entomopathogenic fungus Aschersonia placenta against the whitefly Bemisia tabaci. Can J Microbiol 59: 97-101, 2013.

22. Nong X, Fang CL, Wang JH, et al: Acaricidal activity of extract from Eupatorium adenophorum against the Psoroptes cuniculi and Sarcoptes scabiei in vitro. Vet Parasitol 187: 345-349, 2012.

23. Nong X, Li SH, Chen FZ, et al: Isolation and identification of acaricidal compounds in Eupatorium adenophorum petroleum ether extract and determination of their acaricidal activity against Psoroptes cuniculi. Vet Parasitol 203: 197-202, 2014.

24. Abdel-Ghaffar F and Semmler M: Efficacy of neem seed extract shampoo on head lice of naturally infected humans in Egypt. Parasitol Res 100: 329-332, 2007.

25. Du YH, Li JL, Jia RY, et al: Acaricidal activity of four fractions and octadecanoic acid-tetrahydrofuran-3,4-diyl ester isolated from chloroform extracts of neem (Azadirachta indica) oil against Sarcoptes scabiei var. cuniculi larvae in vitro. Vet Parasitol 163: 175-178, 2009.

26. Rim IS and Jee CH: Acaricidal effects of herb essential oils against Dermatophagoides farinae and D. pteronyssinus (Acari: Pyroglyphidae) and qualitative analysis of a herb Mentha pulegium (pennyroyal). Korean J Parasitol 44: 133-138, 2006.

27. Derda M, Hadaś E and Thiem B: Plant extracts as natural amoebicidal agents. Parasitol Res 104: 705-708, 2009. 